\title{
RESISTÊNCIA DOS FRUTOS DE ABACATE SUBMETIDOS À COMPRESSÃO DURANTE O ARMAZENAMENTO
}

\author{
Acácio Figueiredo Neto ${ }^{1}$, Paulo da Silva Lima Júnior ${ }^{2}$, José Antunes da Silva Neto ${ }^{3}$, Anderson Leandro Nascimento 4 \\ Nelson Cárdenas Olivier ${ }^{5}$
}

\begin{abstract}
RESUMO
Objetivou-se, neste trabalho, determinar os efeitos físicos e químicos do armazenamento do abacate em temperatura ambiente e refrigerado, bem como a resistência à compressão que os mesmos oferecem em diferentes estádios de maturação. Cada fruto foi pesado e aferido suas medidas para avaliação da qualidade e as análises físicas e químicas. As características cor da casca, acidez titulável e sólidos solúveis totais foram avaliadas durante doze dias de armazenamento, em abacates colhidos no mesmo estádio de maturação. Para a determinação da resistência dos frutos, os abacates foram avaliados pelo teste de compressão por duas placas circulares até o seu rompimento. Os resultados indicam que a perda de massa aumenta conforme o fruto vai amadurecendo, os sólidos solúveis totais aumentam até o terceiro dia de armazenamento e, devido ao maior amadurecimento dos abacates armazenados ao ambiente, o $\mathrm{pH} \mathrm{e}$ a acidez são sempre maiores durante o armazenamento dos frutos em ambiente que naqueles abacates armazenados refrigerados. Com relação à cor, os abacates que foram armazenados em ambiente tiveram aumento em luminosidade, croma e redução de ângulo de cor, todos os valores foram maiores que os obtidos em abacates armazenados em refrigerador. Os frutos refrigerados tiveram um aumento da resistência à compressão de $25 \%$ maior em relação aos frutos em temperatura ambiente que tiveram sua força de ruptura reduzida.
\end{abstract}

Palavras-chave: qualidade, danos mecânicos, conservação

\section{ABSTRACT \\ RESISTANCE OF AVOCADO FRUITS SUBJECTED TO COMPRESSION DURING STORAGE}

The objective of this work was to determine the physical and chemical effects of storage on avocados at room temperature and under refrigeration, as well as the compressive strength that they offer in different stages of maturation. Each fruit was weighed and measured to assess the quality and submitted to physical-chemical analysis. The color characteristics of the shell, titratable acidity and total soluble solids were evaluated for twelve days of storage in avocados harvested in the same stage of maturation. To determine the resistance of the fruits, avocados were evaluated by the compression test between two circular plates until its breakup. The results indicate that the weight loss increases as the fruit matures, the total soluble solids increased until the third day due, and due to the increased storage and ripening of avocados stored at ambient conditions, $\mathrm{pH}$ and acidity increased during storing at ambient conditions faster than those stored under chilled conditions. With respect to color, avocados stored at room showed an increase in luminosity, chroma and reduction of hue angle, where all values were higher than those obtained in avocados stored in the refrigerator. The refrigerated fruits had an increased resistance to compression $25 \%$ greater than fruit stored at room temperature which had their breaking strength reduced.

Keywords: quality, mechanical damage, conservation

\section{Recebido para publicação em 18/11/2013. Aprovado em 05/12/2014.}

1 - Eng ${ }^{\circ}$ Agrônomo, Professor Adjunto, Depart ${ }^{\circ}$ de Engenharia Agrícola da UNIVASF, email: acacio.figueiredo@univasf.edu.br

2 - Graduando do curso de Engenharia Agrícola e Ambiental da UNIVASF, Juazeiro - BA.

3 - Graduando do curso de Engenharia Agrícola e Ambiental da UNIVASF, Juazeiro - BA.

4 - Graduando do curso de Engenharia Agrícola e Ambiental da UNIVASF, Juazeiro - BA.

5 - Eng ${ }^{\circ}$ Mecânico, Professor Adjunto do curso de Engenharia Mecânica da UNIVASF, Juazeiro - BA. 


\section{INTRODUÇ̃̃O}

O abacateiro (Persea americana) é uma fruteira tropical originária do continente americano, tendo o México e a Guatemala como centro de diversidade. As variedades de abacate preferidas para consumo no Brasil geralmente apresentam baixo teor de óleo e frutos grandes (FISCHER et al., 2011). É um fruto climatério onde suas fases de maturação acontecem após a colheita, devido ao aumento da sua taxa de respiração (CHITARRA ; CHITARRA, 2005). No entanto, os frutos não devem ser colhidos muito jovens, pois podem ocorrer perdas nas suas qualidades organolépticas.

A produção nacional do abacate está distribuída principalmente nas regiões Sudeste, Nordeste e Sul, sendo o estado de São Paulo o maior produtor, com aproximadamente 77.000 mil toneladas em 2008 (47,5\% do total nacional) e a região Nordeste com 15.403 toneladas, ocupando $15,6 \%$ da área plantada no Brasil (IBGE, 2010).

Na produção brasileira de frutos muitas perdas são geradas devido ao mau manuseio dos frutos na fase de pós-colheita. Dessa forma, o fruto pode acabar sofrendo injurias mecânicas, que são rupturas superficiais, deformações plásticas e destruição do tecido vegetal, provocadas por forças externas, gerando perda de vários dos mais importantes atributos de qualidade, promovendo a rejeição por parte do consumidor. $\mathrm{O}$ impacto e a compressão são causados por forças que acabam levando o fruto à alterações físicas, químicas, fisiológicas e bioquímicas que modificam aroma, textura, cor e sabor, ou seja, contribuindo para má qualidade do produto (MOHSENIN, 1986).

A maioria dos frutos de abacate, comercializados na região do Vale do São Francisco, é produzido por pequenos produtores que possuem pouco conhecimento tecnológico e não possuem infraestrutura adequada para ofertar frutos de qualidade.

$\mathrm{Na}$ comercialização do produto é possível verificar a carência de cuidados no manuseio dos frutos. Os danos ocasionados por injúrias mecânicas são frequentes, dos quais é comum a ocorrência de impactos, compressões e pequenos cortes. Esses danos proporcionam uma porta para entrada de microrganismos que contribuem para o processo de deterioração, desvalorizando os produtos para comercialização, assim como, acelerando o processo de amadurecimento.

O dano mecânico causado pelo impacto geralmente acontece quando o fruto colide com superfícies sólidas ou com outros frutos durante a colheita e pós-colheita. Este causa alguns prejuízos ao fruto, como rupturas ou não na epiderme. Tal injúria também é responsável pela retirada da primeira linha de defesa do fruto, permitindo a entrada de patógenos. Os danos podem não causar alterações externas imediatamente observáveis, mas seu efeito pode acabar gerando, mais tarde, a produção de danos internos (SANCHES et al., 2008).

A injúria mecânica por compressão se dá por uma pressão variável contra a superfície do produto, seja pela parede das embalagens ou por outro fruto adjacente. No abacate não surge o efeito imediato de danos externos antes da maturação, só quando ela chega nesta fase é que se observa a polpa parcial ou totalmente escura (BLEINROTH; CASTRO, 1992).

Desta forma, o presente estudo tem como objetivo determinar os efeitos físicos e químicos do armazenamento do abacate em ambiente á $25^{\circ} \mathrm{C} \pm 2$ e refrigerado, bem como a resistência à compressão que os mesmos oferecem em diferentes estádios de maturação.

\section{MATERIAL E MÉTODOS}

Para condução do experimento foram utilizados frutos de abacate da variedade 'Geada', colhidos cuidadosamente em plantios comerciais localizados no município de Juazeiro (BA). Os mesmos foram conduzidos para o Laboratório de Armazenamento de Produtos Agrícolas (LAPA) do Colegiado de Engenharia Agrícola e Ambiental da UNIVASF, Campus Juazeiro (BA), para posterior caracterização dos parâmetros físicos e químicos e os devidos ensaios de compressão. Com a separação e limpeza dos frutos foram feitas as determinações referentes à massa fresca através da pesagem individual em uma balança semi-analítica, com precisão de $0,1 \mathrm{~g}$, onde todas as pesagens foram expressas em gramas (g), e o formato foi determinado através da relação do comprimento, 
largura e espessura, medidos com o auxílio de um paquímetro digital.

Após as avaliações iniciais dos frutos, os mesmos foram subdivididos em três amostras homogêneas, uma contendo apenas três repetições para acompanhamento da massa fresca, e duas para acompanhamento das análises físicas e químicas e de compressão, sendo uma armazenada em temperatura ambiente de $25{ }^{\circ} \mathrm{C} \pm 2$ e outra refrigerada a $12{ }^{\circ} \mathrm{C}$. As análises foram realizadas de três em três dias, contemplando cinco estádios de maturação do fruto, contando a partir do tempo zero, referente ao dia de chegada ao laboratório.

Nas análises físicas e químicas, as amostras de três repetições foram trabalhadas como amostra composta, tanto para as armazenadas em temperatura ambiente quanto para as refrigeradas. Essas amostras compostas foram utilizadas para a determinação de sólidos solúveis totais ( $\left.{ }^{\circ} \mathrm{Brix}\right)$ através de um refratômetro digital; na determinação do $\mathrm{pH}$, utilizando a técnica potenciométrica através do pHmetro digital, de acordo com a metodologia descrita pelo INSTITUTO ADOLFO LUTZ (2008), e na técnica da determinação da acidez total titulável (ATT), realizada através da titulometria com solução de $\mathrm{NaOH} 0,1 \mathrm{~mol}_{c} \mathrm{~L}^{-1}$, e reagente fenolftaleína a $0,1 \%$, expressando os resultados em percentagem (\%) de ácido cítrico na massa fresca.

Para a determinação da coloração da casca foi utilizado o Colorímetro Minolta, modelo CR-400, o qual expressa a cor em três parâmetros: L, que corresponde a luminosidade (brilho, claridade ou reflectância; 0-escuro/opaco e 100-branco); C, a croma (saturação ou intensidade da cor; 0 -cor impura e 60-cor pura); e H, o ângulo Hue (ângulo da cor; $0^{\circ}$-vermelha; $90^{\circ}$-amarelo; $180^{\circ}$-verde; $270^{\circ}$-azul e $360^{\circ}$-negro).

Para a determinação da compressão foi utilizado o equipamento Emic DL10000, para análise de compressão, pertencente ao Laboratório de Ensaios do colegiado de Engenharia Mecânica. O mesmo foi configurado através do software Tesc versão 3.04, em modelo de análise de compressão e a uma velocidade constante de $5 \mathrm{~mm} \mathrm{~min}^{-1}$.

Os resultados foram exportados para um programa computacional onde foram gerados os gráficos de força $\mathrm{x}$ deformação e um gráfico de Tensão x Deformação de Hencky. Os abacates foram colocados entre duas placas circulares de aço que se movimentavam a velocidade constante, no sentido de se aproximarem, realizando desta forma os ensaios de compressão. Para confecção de Tensão x Deformação foi utilizada uma placa com $30 \mathrm{~mm}$ de diâmetro, que comprimia o fruto até o rompimento, obtendo o momento exato do ponto de ruptura.

O delineamento experimental foi o inteiramente casualizado, em fatorial com a análise de dois fatores, estádios de maturação e condição de armazenamento, com três repetições. Os dados obtidos foram submetidos à análise de variância para verificar quais tratamentos diferiram e em seguida foi aplicado o teste de Tukey, estabelecendo-se o nível mínimo de significância de $5 \%$ ( $\mathrm{p} \leq 0,05)$, utilizando o software ASSISTAT versão 7.6 (SILVA ; AZEVEDO, 2002).

\section{RESULTADOS E DISCUSSÃO}

Diante do que foi analisado físico e quimicamente nos frutos de abacate variedade Geada, os resultados da análise estatística estão dispostos no Quadro 1. A caracterização dos frutos armazenados em ambiente indica que, em média, o comprimento foi de 13,09 $\mathrm{cm}$, largura de 9,00 $\mathrm{cm}$ e espessura de $8,68 \mathrm{~cm}$. A caracterização dos frutos armazenados refrigerados em média tinha o comprimento de $13,30 \mathrm{~cm}$, largura de $8,96 \mathrm{~cm} \mathrm{e}$ espessura de $8,58 \mathrm{~cm}$.

De acordo com a análise de variância e as interações, o fator tempo de armazenamento foi significativo ao nível de $1 \%$ para a croma e o ângulo de cor, enquanto para o fator luminosidade foi de $5 \%$.

$\mathrm{Na}$ interação entre os fatores, a análise de variância foi significativa ao nível de $1 \%$ para croma, luminosidade e o ângulo de cor, indicando que os resultados analisados nos meios de armazenamento são dependentes do tempo de conservação. Este primeiro atributo é o mais importante no processo de escolha de um produto pelos consumidores (DURIGAN; MATTIUZ, 2007), e para abacate da variedade Geada a coloração externa está diretamente ligada á qualidade comercial desta fruta.

Observou-seumapequena evolução da coloração 
Quadro 1. Síntese da análise de variância dos valores médios de luminosidade, croma e ângulo de cor

\begin{tabular}{c|ccc}
\hline Fatores & \multicolumn{3}{|c}{ Cor } \\
\hline Tempo $(\mathrm{T})$ & $\mathrm{L}$ & $\mathrm{C}$ & $\mathrm{H}$ \\
\hline Zero dia & $45,86 \mathrm{~b}$ & $31,35 \mathrm{~b}$ & $120,57 \mathrm{a}$ \\
Três dias & $48,09 \mathrm{ab}$ & $39,53 \mathrm{a}$ & $117,94 \mathrm{a}$ \\
Seis dias & $51,03 \mathrm{ab}$ & $44,06 \mathrm{a}$ & $115,03 \mathrm{a}$ \\
Nove dias & $52,24 \mathrm{a}$ & $44,91 \mathrm{a}$ & $105,14 \mathrm{~b}$ \\
\hline Armazenamento (A) & & & $109,81 \mathrm{~b}$ \\
\hline Ambiente & $53,92 \mathrm{a}$ & $119,53 \mathrm{a}$ \\
\hline Refrigerado & $44,69 \mathrm{~b}$ & $42,31 \mathrm{a}$ \\
\hline Teste F & & $36,12 \mathrm{~b}$ & $16,56^{* *}$ \\
\hline T & $4,45^{*}$ & & $34,42^{* *}$ \\
A & $45,61^{* *}$ & $9,33^{* *}$ & $14,75^{* *}$ \\
T x A & $10,25^{* *}$ & $5,35^{* *}$ & 3,54 \\
CV (\%) & 6,79 & 11,38 & \\
\hline
\end{tabular}

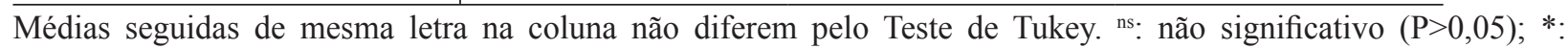
significativo $(\mathrm{P} \leq 0,05)$; **: significativo $(\mathrm{P} \leq 0,01)$. CV.: coeficiente de variação (\%).

da casca, principalmente nos frutos submetidos à análise da luminosidade a partir do terceiro dia. Entre os ambientes de armazenamento, verificase que houve diferença estatística considerável para os três parâmetros de cor: luminosidade, croma e ângulo de cor com manutenção da cor verde para condições refrigeradas, resultado este que corroboram com o retardamento do processo de amadurecimento de abacate da variedade Hass armazenados a $25^{\circ} \mathrm{C}$ (FISCHER et al, 2011).

Estes dados evoluíram de 31,35 no primeiro dia de análise para 44,91 em nove dias, mostrando que a intensidade do pigmento verde aumentou rapidamente após o terceiro dia.

Segundo o teste de Tukey, aplicado aos resultados de luminosidade, o valor aumenta conforme o tempo de armazenamento aumenta. Isso é explicado pelo fato de que os frutos por serem climatéricos estão em processo de amadurecimento. Em se tratando do meio de armazenamento, os valores de luminosidade são estatisticamente diferentes, relatando, assim, que o meio em que os abacates Geada foram armazenados afeta diretamente nos resultados do valor de luminosidade, sendo maior, neste caso, no meio onde a temperatura era ambiente, ou seja, os frutos ficam maduros mais rápidos que aqueles refrigerados á $12{ }^{\circ} \mathrm{C}$. Segundo Sanches (2008), após o terceiro dia de escurecimento, devido ao impacto sofrido pelo fruto, a casca irá aumentar a sua luminosidade devido o amadurecimento do fruto armazenado em ambiente controlado a $25^{\circ} \mathrm{C}$.

Com relação ao valor de croma, o teste de Tukey mostra que o valor aumenta até o sexto dia de armazenamento, havendo uma redução no nono dia estudado. Estatisticamente não há diferença nos valores de croma entre o terceiro e nono dia de armazenamento. Os resultados obtidos aqui diferem dos analisados por Sanches (2008) na etapa 01, pois para as condições em estudo ocorre uma tendência de redução na cromaticidade dos frutos, enquanto neste estudo notou-se um aumento no croma, o que mostra similaridade com a etapa 02 do mesmo trabalho. O meio com que os frutos são armazenados também interfere no valor de croma, sendo o maior verificado na condição ambiente a $25^{\circ} \mathrm{C} \pm 2$.

$\mathrm{O}$ valor de ângulo de cor reduziu conforme aumentou o tempo de armazenamento. Em relação ao meio de armazenamento, houve uma diferença entre eles, porém, diferentemente do que foi observado para luminosidade e para o croma, os

\section{REVENG}


maiores valores foram para o meio em temperatura refrigerado. De acordo com Sanches (2008), ao longo do período de armazenamento ao ambiente, o ângulo de cor $(\mathrm{H})$ reduziu, mesmo não havendo diferença significativa entre os tratamentos. Em abacate Fuerte houve apenas efeito do tempo de armazenamento, com redução média do ângulo de cor $(\mathrm{H})$ após 21 dias de armazenamento a $25{ }^{\circ} \mathrm{C}$ (FISCHER, 2011).

De acordo com a análise de compressão, os abacates que foram armazenados em ambiente (25 $\left.{ }^{\circ} \mathrm{C} \pm 2\right)$ tiveram notável redução da força $(\mathrm{em} \mathrm{N})$, utilizada para romper a casca ao longo do tempo armazenado, sendo a maior igual que $1466,30 \mathrm{~N}$, para o teste do dia da colheita (dia zero), o que já era esperado devido o amadurecimento do fruto. Quanto ao deslocamento vertical, praticamente em todos os testes os abacates se romperam em um ponto próximo a $26 \mathrm{~mm}$ (Figura 1).

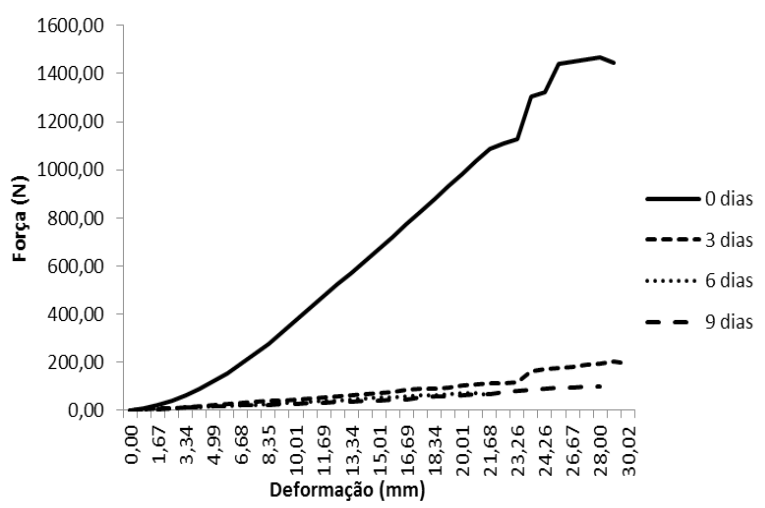

Figura 1. Comportamento do teste de compressão em abacates armazenados em ambiente

Os testes de compressão para os frutos refrigerados (Figura 2) mostram que, após o primeiro dia, os frutos apresentaram maior resistência, pois, no teste do $3^{\circ}$ dia o fruto se rompeu com força de $1771,00 \mathrm{~N}$. Posteriormente, no sexto dia, a força utilizada até o rompimento foi inferior à utilizada no dia zero, pois, mesmo refrigerados, os frutos lentamente estão amadurecendo. No nono dia, a força de ruptura apresentou valores com média de $2054,15 \mathrm{~N}$, sendo esta superior a valores encontrados no $6^{\circ}$ e $3^{\circ}$ dia. No $12^{\circ}$ dia a força de ruptura utilizada foi inferior a força encontrada no $6^{\circ}$ dia de compressão. Quanto ao deslocamento até a ruptura, a maioria dos frutos apresentam ponto de ruptura próximos a $26 \mathrm{~mm}$ de deformação.

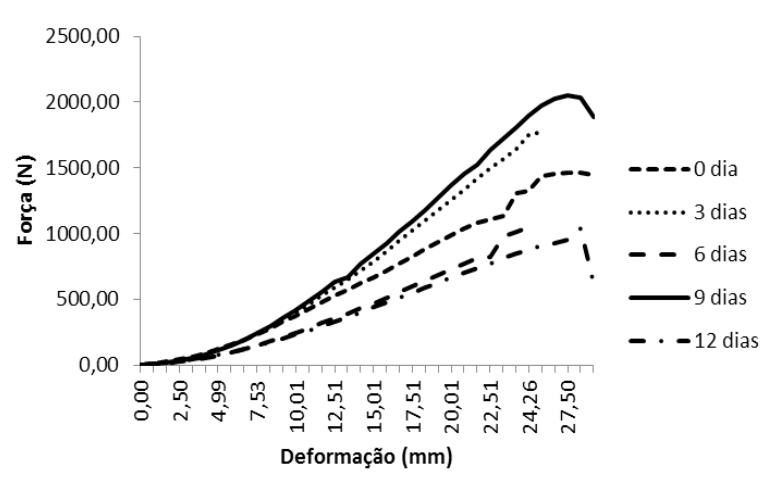

Figura 2. Comportamento do teste de compressão em abacates armazenados com refrigeração.

$\mathrm{Na}$ condição de armazenagem em temperatura ambiente a $25{ }^{\circ} \mathrm{C}( \pm 2)$ ocorreu um maior amadurecimento dos frutos armazenado em temperatura ambiente. Nos testes de compressão fica visível este fato, pois no $12^{\circ}$ dia de teste não houve como fazer compressão nestes frutos, pois para romper sua casca foi necessário aplicar uma força de $1036,00 \mathrm{~N}$, muito acima dos 100,00 $\mathrm{N}$ do nono dia. O deslocamento vertical é interrompido devido ao rompimento da casca para ambos os meios de armazenamento, onde a maioria ficou em torno de $26 \mathrm{~mm}$.

De acordo com o gráficode Tensão x Deformação (Figura 3) foi possível calcular o trabalho de ruptura. $\mathrm{O}$ mesmo é igual à área sobre a curva $\mathrm{e}$ com valor igual a $0,29 \mathrm{MJ} \mathrm{m}^{-3}$. Segundo Sato et al. (2004), o trabalho na ruptura é o parâmetro que melhor se correlaciona com a energia necessária para a mordida.

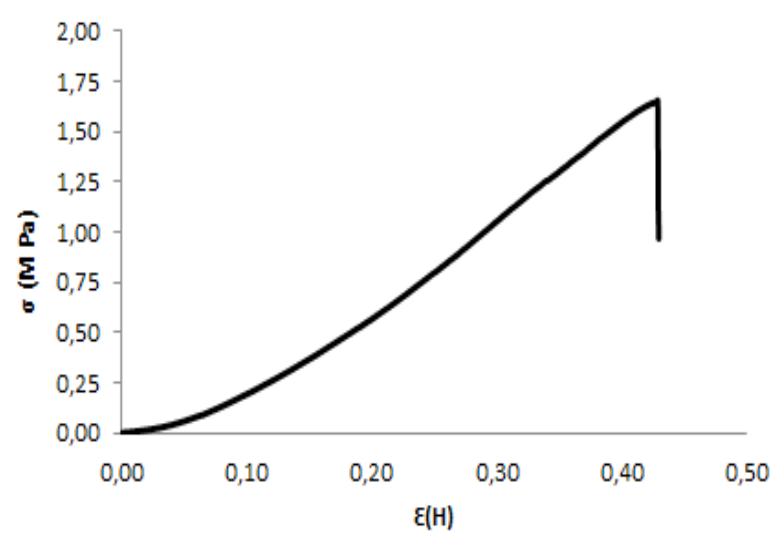

Figura 3. Propriedade mecânica dadas pela curva de Tensão x Deformação de Hencky. 
A análise de variância realizada para perda de peso foi significativa ao nível de $1 \%$ para os fatores tempo e meio de armazenamento, indicando não haver semelhança entre os valores encontrados. Sobre a interação entre os fatores nas condições de armazenagem, não houve dependência entre os fatores no que se refere a perda de massa.

Aplicando o teste de Tukey no fator tempo de armazenamento, foi verificado que a perda de peso aumenta com o passar do tempo, independentemente do meio em que os abacates da variedade Geada são armazenados. Quando aplicamos o teste de Tukey no fator de condições de armazenamento, notamos que aqueles abacates que foram armazenados ao ambiente $\left(25^{\circ} \mathrm{C} \pm 2\right)$ perdem mais peso que os armazenados em meio refrigerado. Pela comparação entre as condições, podemos ressaltar a importância do armazenamento em meio refrigerado pelo fato de que podemos conservar os frutos por um intervalo de tempo maior.

Segundo Ramos et al. (2012), estudando danos mecânicos na qualidade pós-colheita em três variedades de maçãs armazenadas a $1{ }^{\circ} \mathrm{C}$, a desidratação aumentou ao longo da armazenagem em todos os tratamentos, resultado este que se equivale aos observados em condições refrigerada.

De acordo com a análise de regressão linear, o resultado foi significativo ao nível de $1 \%$ em ambos as condições de armazenamento (Figura 4). Caso seja necessário o conhecimento de qualquer outro valor em um tempo não estudado, pode-se utilizar a função $\mathrm{y}=2,46 \mathrm{x}-0,72$, com $\mathrm{R}^{2}=0,98$, para o armazenamento em ambiente e a função $\mathrm{y}=$ $1,36 \mathrm{x}-1,90$, com $\mathrm{R}^{2}=0,80$, para o armazenamento refrigerado.

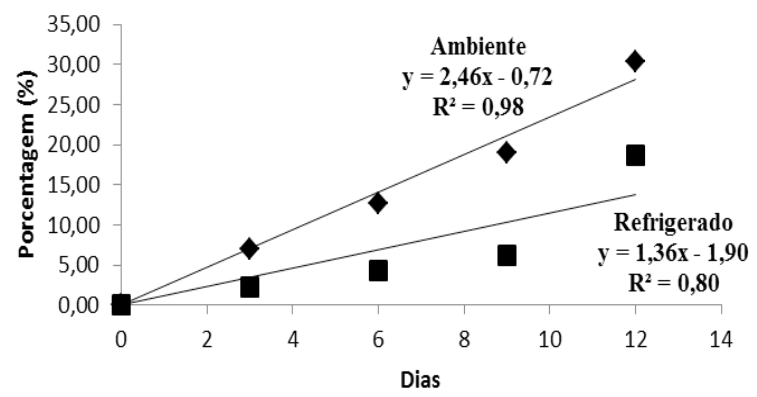

Figura 4. Análises de regressão para perda de massa em duas condições de armazenagem.

Quadro 2. Síntese da análise de variância dos valores médios da perda de massa, sólidos solúveis totais, $\mathrm{pH}$ e acidez

\begin{tabular}{ccccc}
\hline Fatores & $\begin{array}{c}\text { Perda de massa } \\
(\mathrm{g})\end{array}$ & $\begin{array}{c}\text { Sólidos solúveis } \\
\text { totais }\left({ }^{\circ} \text { Brix }\right)\end{array}$ & $\mathrm{pH}$ & Acidez (\%) \\
\hline Tempo (T) & & & & \\
\hline Zero dia & $0,0 \mathrm{~d}$ & $9,30 \mathrm{~b}$ & $6,57 \mathrm{a}$ & $2,34 \mathrm{~b}$ \\
Três dias & $4,77 \mathrm{~cd}$ & $10,87 \mathrm{a}$ & $6,43 \mathrm{ab}$ & $11,31 \mathrm{a}$ \\
Seis dias & $8,62 \mathrm{bc}$ & $10,20 \mathrm{ab}$ & $6,25 \mathrm{c}$ & $11,31 \mathrm{a}$ \\
Nove dias & $12,73 \mathrm{~b}$ & $9,90 \mathrm{ab}$ & $6,32 \mathrm{bc}$ & $12,37 \mathrm{a}$ \\
Doze dias & $24,70 \mathrm{a}$ & - & - & - \\
\hline Armazenamento (A) & & & $6,30 \mathrm{~b}$ & $10,18 \mathrm{a}$ \\
\hline Ambiente & $14,06 \mathrm{a}$ & $9,89 \mathrm{a}$ & $8,48 \mathrm{~b}$ \\
Refrigerado & $6,27 \mathrm{~b}$ & $10,24 \mathrm{a}$ & $6,48 \mathrm{a}$ & \\
\hline Teste F & & & $12,67 * *$ \\
T & $29,53 * *$ & $22,00 * *$ & $11,38^{* *}$ \\
A & $25,42 * *$ & $5,91 * *$ & $5,15 *$ & $2,01 \mathrm{~ns}$ \\
T x A & $2,49 \mathrm{~ns}$ & $1,71 \mathrm{~ns}$ & 1,50 & 13,28 \\
\hline CV (\%) & 41,65 & $6,52 \mathrm{~ns}$ & & \\
\hline
\end{tabular}

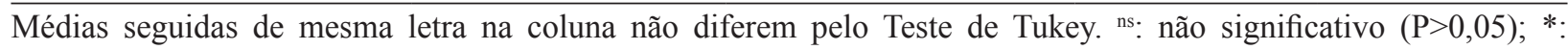
significativo $(\mathrm{P} \leq 0,05)$; **: significativo $(\mathrm{P} \leq 0,01)$. CV.: coeficiente de variação (\%) 
Com relação aos sólidos solúveis, o teste $\mathrm{f}$ foi significativo em nível de $1 \%$ para o fator tempo de armazenamento e não foi significativo nem para o fator meio de armazenamento e nem na interação entre os fatores, o que indica a não dependência entre eles.

O teste de Tukey aplicado indica que os sólidos solúveis totais aumentam até o terceiro dia de armazenamento e decresce posteriormente. Quanto aos meios de armazenamento, o valor obtido de sólidos solúveis totais no meio "refrigerado" foi estatisticamente igual ao da condição ambiente a $25^{\circ} \mathrm{C} \pm 2$, conforme apresentado no Quadro 2 .

De acordo com Sanches (2008), há uma tendência de redução dos sólidos solúveis totais com o passar do tempo, devido ao amadurecimento dos frutos de abacates armazenados na condição ambiente, e este amadurecimento dos frutos aumenta o teor de óleo, o que aumenta o consumo de carboidratos, principalmente os solúveis. Para Fischer (2011), os teores médios de sólidos solúveis totais de abacate Hass são maiores nos frutos que permaneceram 30 dias na câmara fria $\left(5^{\circ} \mathrm{C}\right)$.

De acordo com a regressão, foi significativa ao nível de $1 \%$ para a condição de armazenamento ambiente, a regressão quadrática cuja função é indicada por $\mathrm{y}=9,38+0,59 \mathrm{x}-0,07 \mathrm{x}^{2}$, onde $\mathrm{o}$ coeficiente de determinação foi $\mathrm{R}^{2}=0,92$ (Figura 5). Para o meio refrigerado não houve uma regressão que identificasse significativamente o comportamento dos sólidos solúveis totais.

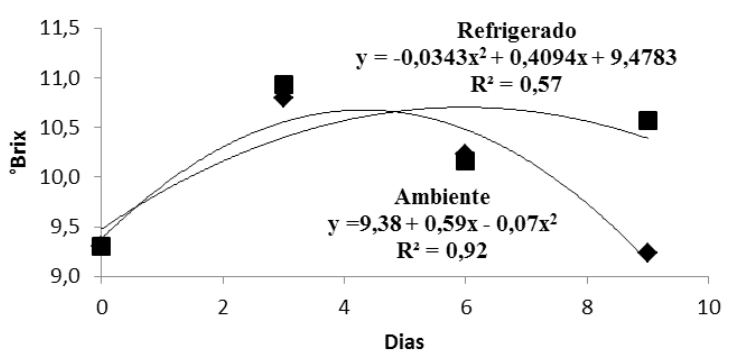

Figura 5. Análises de regressão para sólidos sólidos solúveis totais $\left({ }^{\circ}\right.$ Brix $)$

$\mathrm{O} \mathrm{pH}$ dos abacates foram significativos no teste F em nível de $1 \%$ para os fatores meio e tempo de armazenamento, mostrando que não houve semelhança entre os dados amostrados. Para a interação entre os fatores, o teste $\mathrm{F}$ foi significativo em nível de $5 \%$, o que comprova a dependência entre os fatores no valor de $\mathrm{pH}$, ou seja, os valores analisados dependerá da condição e do tempo em que os abacates foram armazenados.

Para os valores de $\mathrm{pH}$ dos abacates armazenados ocorre uma redução conforme o tempo de armazenamento aumenta. Quando feita a comparação entre os meios de armazenamento, a condição ambiente $\left(25^{\circ} \mathrm{C} \pm 2\right)$ torna o abacate mais ácido que os armazenados na condição de refrigerados conforme apresentado no Quadro 2.

Diante da análise de regressão para o $\mathrm{pH}$ (Figura 6), a condição ambiente $\left(25^{\circ} \mathrm{C} \pm 2\right)$ foi obtida uma regressão linear significativa a $1 \%$ de probabilidade e o refrigerado não obteve significância em nenhuma regressão. Para que possa ser obtido um resultado para qualquer outro tempo de armazenamento ao ambiente, pode ser utilizada a função $\mathrm{y}=6,54$ $-0,05 \mathrm{x}$, onde o coeficiente de determinação é de $\mathrm{R}^{2}$ $=0,86$.

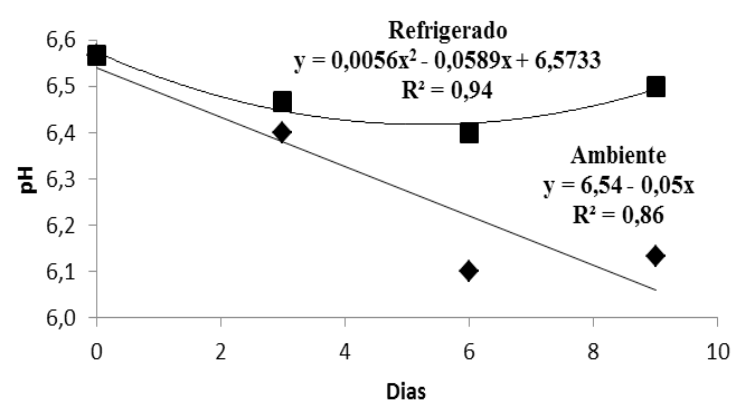

Figura 6. Comportamento das análises de regressão no que se refere ao $\mathrm{pH}$ dos frutos de abacate.

A análise de variância, teste $F$, indica que para a acidez, o fator tempo e a condição de armazenamento foram significativos em nível de $1 \%$ de probabilidade. Porém, não foi significativo na interação entre os fatores, representando não haver dependência entre eles.

Aplicando-se o teste de Tukey, mostra que a acidez aumenta conforme o tempo de armazenamento aumenta. Para o armazenamento na condição ambiente $\left(25^{\circ} \mathrm{C} \pm 2\right)$, o valor da acidez é maior que os encontrados para a condição refrigerado. Tais resultados foram compatíveis com a redução no pH (Quadro 2).

Segundo estudo de Fischer (2011), os teores 
de acidez titulável observados em abacates da variedade Fuerte apresentaram aumento significativo com o armazenamento a $25{ }^{\circ} \mathrm{C}$, resultados semelhantes aos encontrados neste trabalho. De acordo com Fischer (2011), após a retirada dos frutos beneficiados da câmara fria, observou-se que os mesmos apresentavam teores de acidez semelhantes aos dos frutos amostrados na chegada e no palete. Em relação ao abacate da variedade Hass só houve mudança significativa dos teores de acidez a partir do $10^{\circ}$ dia de armazenamento entre os frutos amostrados na chegada e no palete.

De acordo com Kasat (2007), a acidez titulável foi menor nos pêssegos injuriados e diminuiu durante o período de armazenamento dos mesmos. Já para Ramos et al. (2012), a acidez em maçã diminuiu ao longo da armazenagem $\left(1{ }^{\circ} \mathrm{C}\right)$ nas três cultivares estudadas, sem haver diferença significativa entre os tratamentos.

De acordo com a análise de regressão, foi significativa em nível de $1 \%$, para o armazenamento em condição ambiente $\left(25^{\circ} \mathrm{C} \pm 2\right)$, a equação quadrática, em que o $\mathrm{R}^{2}$ é igual a 0,91 . Para o meio "refrigerado" a regressão quadrática também foi significativa em nível de $1 \%$ e com $\mathrm{R}^{2}$ igual a 0,93 (Figura 7).

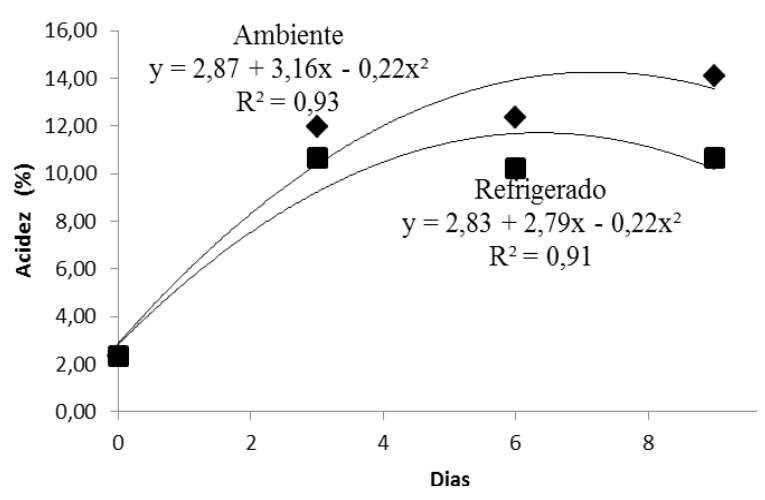

Figura 7. Análises de regressão no que se refere à acidez dos frutos de abacate.

\section{CONCLUSÕES}

- Os frutos refrigerados apresentaram aumento na sua resistência à compressão até o terceiro dia de aramazenamento;

- A força de ruptura foi de 0,29 $\mathrm{MJ} \mathrm{m}^{-3}$, independente da condição de armazenamento;
- Os abacates tiveram rompimento no geral próximo ao deslocamento de $26 \mathrm{~mm}$;

- Os sólidos solúveis solúveis totais aumentaram até o terceiro dia e posteriormente reduziram, não havendo diferença entre os meios de armazenamento;

- A luminosidade, o croma e o ângulo de cor dos abacates variedade Geada que foram armazenados em ambiente $\left(25^{\circ} \mathrm{C} \pm 2\right)$ tiveram aumento em $\mathrm{L}$ e $\mathrm{C}$ e redução de $\mathrm{H}$, sendo todos os valores maiores que os obtidos em abacates refrigerados.

\section{AGRADECIMENTOS}

Os autores agradecem ao CNPq e a UNIVASF pelo apoio financeiro ao projeto de tecnologia pós-colheita na região semiárida do Vale do São Francisco.

\section{REFERÊNCIAS BIBLIOGRÁFICAS}

BLEINROTH, E.W.; CASTRO, J.V. de. Matériaprima. In: ITAL. Abacate: cultura, matéria-prima, processamento e aspectos econômicos. 2.ed. Campinas: ITAL, p.58-148, 1992.

BRASIL. IBGE. Instituto Brasileiro de Geografia e Estatística. http://www.ibge.gov.br/estadosat/. Acesso em: 15 de abr de 2013.

CHITARRA, M.I.F.; CHITARRA, A.D. Póscolheita de frutas e hortaliças: Fisiologia e manuseio. 2ed., Lavras: FAEPE, 2005.785p.

DURIGAN， M.F.B.; MATTIUZ, B. Injúrias mecânicas e seus efeitos na qualidade de melancias armazenadas em condições ambiente. Horticultura Brasileira, v.25, n.2, p.296-300, 2007.

FISCHER, I.H; TOZZE JÚNIOR, H.J; ARRUDA, M.C. de; Massola Júnior, N.S. Pós-colheita de abacates 'Fuerte' e 'Hass': características físicas e químicas, danos e controle de doenças. Ciências Agrárias, Londrina, v.32, n.1, p.209-220, 2011. INSTITUTO ADOLFO LUTZ. Métodos
físico-químicos para análise de alimentos. 
Coordenadores - Odair Zenebon, Neus Sadocco Pascuet e Paulo Tiglea -- São Paulo: Instituto Adolfo Lutz, 2008, 533p.

KASAT, G.F.; MATTIUZ, B.; OGASSAVARA, F.O; BIANCO, M.S; MORGADO, C.M.A; CUNHA JUNIOR, L.C. Injúrias mecânicas e seus efeitos em pêssegos 'aurora-1'. Rev. Bras. Frutic. Jaboticabal, v.29, n.2, p.318-322, 2007.

MOHSENIN, N.N. Physical properties of plant and animal materials: structure, physical characteristics and mechanical properties. 2nd ed. New York: Gordon and Breach, 1986. 891 p.

RAMOS, A.P; PERES, L.G; FRECCIA, C.F.; VITTO, D.C; CARLOS, E.B; PALHANO, W.C; CARDOSO, L. da S.; BELLINI, J.S; SEIBERT, E. Danos mecânicos por impacto, compressão e corte e seus efeitos na qualidade pós-colheita de maçãs. Rev. Técnico Científica (IFSC), v.3, n.1, 2012.

SANCHES, J; DURIGAN, J.F; DURIGAN, M.F.B. Aplicação de danos mecânicos em abacates e seus efeitos na qualidade dos frutos. Eng. Agrícola, Jaboticabal, v.28, n.1, p.164-175, 2008.

SILVA, F.A.S.; AZEVEDO, C.A.V. Versão do programa computacional Assistat para o sistema operacional Windows. Revista Brasileira de Produtos Agroindustriais, v.4, n.1, p.71-78, 2002.

SATO, A.C.K.; SANJINEZ-ARGANDOÑA, E.J.; CUNHA, R.L. Avaliação das propriedades físicas, químicas e sensorial de preferência de goiabas em calda industrializadas. Ciênc. Tecnol. Alimentos, Campinas, p.550-555, 2004. 